NBER WORKING PAPER SERIES

SIMPLE HUMANS, COMPLEX INSURANCE, SUBTLE SUBSIDIES

Jeffrey Liebman

Richard Zeckhauser

Working Paper 14330

http://www.nber.org/papers/w14330

\author{
NATIONAL BUREAU OF ECONOMIC RESEARCH \\ 1050 Massachusetts Avenue \\ Cambridge, MA 02138 \\ September 2008
}

This paper is a chapter in the forthcoming book Using Taxes to Reform Health Insurance: Pitfalls and Promises. Henry J. Aaron and Leonard E. Burman, eds (Washington: Brookings Institution). We are grateful to Henry Aaron, Len Burman, Jeffrey Kling, Edward McCaffery, Eve Rittenberg, and Chris Robert for helpful comments. The views expressed herein are those of the author(s) and do not necessarily reflect the views of the National Bureau of Economic Research.

NBER working papers are circulated for discussion and comment purposes. They have not been peerreviewed or been subject to the review by the NBER Board of Directors that accompanies official NBER publications.

(C) 2008 by Jeffrey Liebman and Richard Zeckhauser. All rights reserved. Short sections of text, not to exceed two paragraphs, may be quoted without explicit permission provided that full credit, including (c) notice, is given to the source. 
Simple Humans, Complex Insurance, Subtle Subsidies

Jeffrey Liebman and Richard Zeckhauser

NBER Working Paper No. 14330

September 2008

JEL No. D80,H2,I11

\begin{abstract}
$\underline{\text { ABSTRACT }}$
The behavioral revolution in economics has demonstrated that human beings often have difficulty making wise choices. The most widely chronicled difficulties arise for decisions made under conditions of uncertainty, those whose consequences unfold over significant amounts of time, and decisions made in complex environments. Unfortunately, these are precisely the elements involved when individuals choose a health insurance policy, or decide whether to consume health care services. In this paper, we argue that traditional economic models of insurance are woefully insufficient for analyzing the tradeoffs inherent when giving consumers responsibility for making health care choices. We show that behavioral economics provides a stronger normative justification for many features of our existing health care policy than do the models of traditional economics. We then demonstrate that policy analyses of the wide range of subsidies that permeate the health care system change substantially when viewed from the behavioral perspective. In closing, we discuss how recent policy trends can be fruitfully assessed using a behavioral lens.
\end{abstract}

Jeffrey Liebman

John F. Kennedy School of Government

Harvard University

79 JFK Street

Cambridge, MA 02138

and NBER

jeffrey_liebman@harvard.edu

Richard Zeckhauser

John F. Kennedy School of Government

Harvard University

79 John F. Kennedy Street

Cambridge, MA 02138

and NBER

richard_zeckhauser@harvard.edu 


\section{Simple Humans, Complex Insurance, Subtle Subsidies ${ }^{*}$ \\ Jeffrey Liebman and Richard Zeckhauser}

\section{Introduction}

The behavioral revolution in economics tells us that human beings often have difficulty making wise choices. The most widely chronicled difficulties in decisionmaking occur in conjunction with decisions made under conditions of uncertainty, decisions that involve significant elements of time, and decisions in complex environments. Unfortunately, these are precisely the factors involved when individuals choose a health insurance policy or choose whether and when to consume health care.

Historically, U.S. consumers have been shielded from many choices about their health care. For most workers under the age of sixty-five, employers have been responsible for designing health insurance plans and have provided employees with a single plan or a simple menu of options. For the elderly and the poor, the government provided a single plan. Traditional plans often provided first-dollar coverage without co-pays, so a consumer's choice about whether to consume health care involved comparing only the inconvenience and discomfort of obtaining care with the potential benefits.

Recent developments have put more choices and more quandaries before health care consumers. Motivated by concerns about rising costs and potential overconsumption by individuals who can obtain incremental health care resources at a price far below the social costs, firms have adopted various forms of managed care. Workers are often offered multiple types of health insurance plans, ranging from traditional indemnity plans to health maintenance organizations, preferred provider organizations, pointof-service plans, and high-deductible plans coupled with savings accounts. ${ }^{1}$ These plans usually charge

\footnotetext{
* This paper is a chapter in the forthcoming book Using Taxes to Reform Health Insurance: Pitfalls and Promises. Henry J. Aaron and Leonard E. Burman, eds (Washington: Brookings Institution). We are grateful to Henry Aaron, Len Burman, Jeffrey Kling, Edward McCaffery, Eve Rittenberg, and Chris Robert for helpful comments.

${ }^{1}$ The Kaiser Family Foundation reports that, in 2007, 50 percent of workers were offered at least two types of plan and 17 percent were offered three or more types. In large firms (200 or more employees), 63 percent of workers were offered two or more types and 23 percent were offered three or more. Data are not available on how many plans of each type were offered. See Kaiser Family Foundation, Employer Health Benefits: 2007 Annual Survey (www.kff.org/insurance/7672).
} 
different co-payments and reimburse a different share of costs for different types of service. They force consumers to weigh money alongside inconvenience and discomfort in deciding whether to obtain care.

Medicare and Medicaid have also sought to foster competition and choice by offering

participants a range of plans, including managed care. In short, for consumers, purchasing health care has become more like buying an automobile, with many models, financial factors, and safety features to consider. Moreover, the trends in policy proposals from both the left and the right are toward options that would shift significant numbers of people away from employer-based coverage, in which employers make many of the tough choices for the consumers, and toward arrangements that would make individuals responsible for making additional, complex choices---first over which insurance plan to purchase and second when and how much health care to consume.

In this paper we argue that traditional economic models of insurance are woefully insufficient for conducting policy analysis of the trade-offs involved in giving consumers increased responsibility for making health care choices. The traditional models need to be supplemented with key concepts from behavioral economics. ${ }^{2}$ The typical analysis that views the design of an optimal health insurance program as setting the right trade-off between risk spreading and appropriate incentives captures neither current realities in the health care marketplace nor humans’ abilities to make rational decisions. Indeed, we argue that behavioral economics provides much more of a normative justification for many of the features of our existing health care policy than do the models of traditional economics. If our argument is accepted, a logical implication is that, because the justifications for those features are not understood, many current policies are poorly designed.

We begin broadly by discussing why behavioral economics provides a useful frame for viewing consumer decisionmaking about health care. We then argue that the policy analysis of the wide range of subsidies that permeate the health care system changes substantially when viewed from the behavioral

\footnotetext{
${ }^{2}$ Others have made similar arguments about supplementing the standard model of insurance with lessons from behavioral economics. See Joseph Newhouse, "Reconsidering the Moral Hazard: Risk Avoidance Tradeoff,” Journal of Health Economics 25 (2006): 1005--14; Michael E. Chernow, Allison B. Rosen, and A. Mark Fendrick, "Value-Based Insurance Design,” Health Affairs (2007): w195--w203.
} 
perspective. Finally, we discuss how recent policy trends can be assessed using that perspective---and how doing so alters the interpretation of the relevant trade-offs.

\section{The Challenge of Health Care Decisionmaking}

We focus primarily on two types of health care choice. The first is the decision of whether to purchase health insurance and, if so, what type and which specific policy. The second is when and whether to obtain health care. ${ }^{3}$ Both types of decision involve uncertainty, time, and complexity, thus bringing behavioral propensities in decisionmaking to the fore. Status quo bias also proves to be an important feature of health care decisionmaking.

\section{Health Decisions under Uncertainty}

In the textbook model, the price charged to consumers for insurance is greater than the average expected claims the consumers will make. For insurance companies to break even, they must charge a price above average expected claims to cover administrative expenses. Prices may also include a pure economic profit if markets are not sufficiently competitive. Even with prices exceeding expected claims, some consumers purchase insurance because they are willing to pay to avoid financial risk. The greater an individual's risk aversion, the greater the amount of insurance that is purchased at a given price. In addition, individuals who know that they face higher than average risks will purchase more insurance, a phenomenon known as adverse selection. In making the decision of how much insurance to buy, the textbook consumer calculates expected utility over the distribution of possible outcomes under each insurance option and then chooses the amount of insurance that maximizes expected utility.

\footnotetext{
${ }^{3}$ There is a large medical literature on ways to help patients make "good" decisions about which medical treatments to undergo. For a survey see Peter Ubel, “Beyond Knowledge: Figuring Out How to Help People Make “Good” Decisions,” University of Michigan, 2007. Our focus is not on helping people make good decisions per se but instead on how the financial incentives in health insurance plans and government policies should be designed given what is known about how people make health care decisions.
} 
Health insurance as commonly found in the United States presents a more complex set of decisions, though in theory the same expected-utility model would dictate choices. Thus, for each insurance option a utility would be computed for the financial consequences of each possible illness the consumer could experience during the year. These utility values would be weighted by the probability that an illness occurs to produce an expected utility for each plan. The highest yielding plan would then be chosen. Matters are simplified because individuals can select only among a specified set of policies and rarely can choose more or less coverage on a particular policy. But the insurance choice decision is much more complex than with, for example, homeowners' or life insurance because there are so many possible "loss events," including many that are unfamiliar to the consumer. Each individual faces differing risks of the various possible medical conditions, risk levels that are extremely hard to assess. Beyond this, initial choices to secure care enmesh the individual in a stream of options that lead to further care and further expense for both the consumer and the health plan. To illustrate, a positive screening for prostate cancer may lead to half a dozen treatment options, each with different consequences for expenditures, both by the individual and by his insurance plan, and for his quality of life and survival. It is almost impossible for individuals to make sensible decisions when confronted with so many material secondary branches sprouting from so many main branches along the decision tree.

Even conscientious students of decision analysis would be challenged in attempting to purchase health insurance on a rational basis. To figure out which health insurance choice maximizes expected utility, one needs to know the probabilities, financial costs, and health-related utilities associated with each possible state of the world. Securing knowledge on any of these components is problematic.

Start with the probabilities. Ask yourself, what is the chance that you will have a heart attack this year? Or that you will be diagnosed with cancer? Or that you will need back surgery? Is there any chance that an ordinary person knows such probabilities within a factor of five? The challenge here is not simply lack of data. The behavioral economics literature tells us that most individuals make 
systematic mistakes in assessing probabilities. One type of error involves homogenizing probabilities. People do not distinguish sufficiently between a 5 percent chance and 20 percent chance or, for that matter, between a 1 percent chance and a 5 percent chance. ${ }^{4}$ But they draw a big distinction between 1 percent and 0 percent. In addition, individuals are much too confident of their estimates; when subjects were asked to give a series of 98 percent confidence intervals around a list of unknown quantities, the true value lay outside the interval provided by the subjects a whopping 43 percent of the time. ${ }^{5}$

This is bad news for individuals making decisions about insurance for medical care. There are hundreds of possible events, many of which involve exactly the sort of small probabilities where judgment is the worst. If people are too confident about what they know, they will be unlikely to contemplate extreme events, such as a car accident or a cancer episode that will cause them to be in the hospital for weeks. ${ }^{6}$ If so, they will purchase too little insurance. On the other hand, they may give excess weight to salient low-probability events (such as dying in an airplane crash) and overinsure. ${ }^{7}$

The challenge of assessing probabilities is compounded by the problem of predicting the financial costs should one of these conditions arise. Given that the medical system presents different prices to different consumers---typically higher prices for those paying out of pocket---there is no convenient place where one could look up these prices. Informal surveys suggest that even individuals covered by insurance have little idea of how much it would cost them to be treated for something like lung cancer or a heart attack.

We have talked only about financial costs, but health care decisions involve far more. The payoffs in different states of the world involve not just financial amounts but also health-related utilities.

\footnotetext{
${ }^{4}$ See Daniel Kahneman and Amos Tversky, “Prospect Theory: An Analysis of Decision under Risk,” Econometrica 47 (1979): 263--91.

${ }^{5}$ Marc Alpert and Howard Raiffa, “A Progress Report on the Training of Probability Assessors,” in Judgment under Uncertainty: Heuristics and Biases, edited by Daniel Kahneman, Paul Slovic, and Amos Tversky (Cambridge University Press, 1982). This overconfidence result has been replicated hundreds of times.

${ }^{6}$ See also Kunreuther's work showing that people do not buy insurance against floods even when they are in a flood zone. Howard Kunreuther and others, Disaster Insurance Protection: Public Policy Lessons (Hoboken, N.J.: Wiley Interscience, 1978).

${ }^{7}$ A particularly bizarre type of overinsurance---the purchase of extended warranties for consumer durables---is discussed in David Cutler and Richard Zeckhauser, "Extending the Theory to Meet the Practice of Insurance,” Brookings-Wharton Papers on Financial Services (2004): 1-53.
} 
Assessing utilities, for example, of coping with a deteriorated medical condition because one failed to treat it earlier presents its own challenge. How terrible would it be to live with diabetes in one's sixties? What would a person pay to avoid needing cataract surgery or to avoid one chance in a hundred of dying at age sixty?

In this analysis, we assess health-related utilities in quality-adjusted life years, which go by the acronym QALYs. Evidence of the difficulty of answering the questions just asked is seen in the disparities in the QALY literature between assessments made by doctors and other medical professionals and assessments generated by asking people with those same conditions: people living with the conditions generally find them less horrible than do medical professionals. ${ }^{8}$ A similar disparity arises among patients judging before rather than after the fact. Evidence suggests that individuals living with an unpleasant condition, say incontinence after prostate surgery, generally rate it less unfavorably than those who are contemplating the possibility of the condition when they are deciding about treatment. More generally, individuals overestimate how strongly good or bad outcomes will affect their happiness. ${ }^{9}$ Given that medical surprises are mostly on the downside, and much of adult life involves a downhill health slide, it is fortunate that there is a lot of inertia in our self-perceptions of well-being.

Since it is unlikely that ordinary consumers know their own probabilities, associated costs, and health utilities, how can they make informed decisions about what insurance to buy? One possibility is that consumers could ask their physicians. Health care represents a quintessential example of a principal-agent relationship, where the physician is the supposedly well-informed agent, acting faithfully on behalf of the patient principal. In practice, this is an unpromising strategy. Research indicates that physicians themselves exhibit the same sorts of cognitive biases that afflict patients. Even in the much more manageable circumstance where a patient already has a particular condition, doctors are often loath to assess probabilities, as anyone who has asked a doctor to do so knows well. Two common

\footnotetext{
${ }^{8}$ Christopher J. L. Murray, "Rethinking DALYs,” in The Global Burden of Disease: A Comprehensive Assessment, edited by Christopher J. L. Murray and Alan D. Lopez (Harvard University Press, 1996).

${ }^{9}$ Daniel Gilbert, Stumbling on Happiness (New York: Knopf, 2006).
} 
responses are, "It is impossible to put a probability on it,” and "It all depends on the particular patient." Moreover, doctors generally are not inclined to give advice on choice of health insurance plan.

Another way to make informed decisions might be to observe the experiences of friends and coworkers who have chosen various insurance arrangements, including self-insurance. But given the large number of low-probability health events that could strike an individual, this technique would yield a poor estimate of the distribution of one's personal outcomes under such arrangements. Presumably, humans have some common heuristics for extrapolating from common occurrences to rare events. But the experience with probability assessment and with probability scaling (prospect theory) suggests that these methods are far from reliable for individuals who must cope with low-probability, highconsequence risks. ${ }^{10}$ This lack of reliability should not be all that surprising. After all, prehistoric man did not buy health insurance. Primitive humans daily confronted high-probability, high-consequence risks; low-probability risks were a minor concern. ${ }^{11}$

\section{Decisionmaking over Periods of Time}

Many health care choices impose immediate costs to produce future benefits. These decisions include whether to contract for health insurance today that will generate financial protection later in the year and possibly guarantee access to coverage for future years, whether to have a painful or expensive medical procedure today that may yield health benefits in the future, and whether to invest money or effort now in preventive care. ${ }^{12}$

A central finding of behavioral economics is that people tend to underinvest in these sorts of activity, placing excessive weight on current-period costs and underweighting next-period benefits.

\footnotetext{
${ }^{10}$ Alpert and Raiffa, “A Progress Report.”

${ }^{11}$ Incidentally, if one does learn from peers, having more options for the group is likely a disadvantage, since there will not be much information on most alternatives. Concentrated choices yield more information.

${ }^{12}$ A separate set of health decisions, mostly in the category of health behaviors, involves actions that have current benefits but generates health costs in the future. Health policy on how to reduce smoking, obesity, and sexually transmitted diseases fits in this category. Recently developed behavioral models apply to these circumstances. See Jonathan Gruber and Botond Koszegi, “Is Addiction 'Rational'? Theory And Evidence,” Quarterly Journal of Economics 116, no. 4 (2001): 1261--303; B. Douglas Bernheim and Antonio Rangel, “Addiction and Cue-Triggered Decision Processes,” American Economic Review (2004): 1558--90.
} 
Interestingly, though most individuals use a big discount factor between today and tomorrow (where tomorrow should be interpreted metaphorically), their trade-off rates between tomorrow and the next day are often consistent with what economists would prescribe. This behavior pattern is called hyperbolic discounting. ${ }^{13}$ As should be obvious, such preferences lead to procrastination, putting something unpleasant off for another day. They also lead to dynamic inconsistency, since one’s plans to take action tomorrow get postponed again when tomorrow becomes today.

Liquidity constraints (the inability to borrow against future income) provide a more conventional explanation of why people underconsume goods that involve current costs but offer more-thancompensating future payoffs. This explanation is particularly relevant among households that are younger, in the lower part of the income distribution, or locked into lumpy consumption commitments such as home mortgages for which there are high costs of revising consumption levels. But to explain phenomena we should not just take refuge in the easiest rational explanation. Procrastination must compete along with liquidity constraints as a potential explanation even for this group’s underconsumption of future-oriented goods.

Psychology provides evidence of another behavioral factor that may cause people to underinvest in future health: people do not like to contemplate bad outcomes, particularly death, and therefore make decisions that ignore or underestimate the possibility of these adverse outcomes. ${ }^{14}$ Others have applied these insights to economic decisions such as the failure to make inter vivos gifts, purchase life insurance, and draw up wills. ${ }^{15}$ Insights about bad-outcome denial apply with particular force to health care consumption decisions and may well be the strongest explanation for why middle-aged men are notorious for not obtaining annual checkups. This mechanism may also partly explain why some patients fail to take the medicines prescribed for their chronic conditions, neglect to do the stretching exercises that would ameliorate future back pain, or refuse to get tested for HIV.

\footnotetext{
${ }^{13}$ David Laibson, “Golden Eggs and Hyperbolic Discounting,” Quarterly Journal of Economics 112, no. 2 (1997): $443--77$.

${ }^{14}$ Robert Kastenbaum, The Psychology of Death, 3rd ed. (New York: Springer, 2000).

${ }^{15}$ Wojciech Kopczuk and Joel Slemrod, “Denial of Death and Economic Behavior,” Advances in Theoretical Economics 5, no. 1 (2005): 1207.
} 


\section{Decisionmaking in Complex Environments}

Choosing a health insurance plan is more challenging and perilous than most purchasing decisions. Health plans are complex and rife with hidden subsidies, making it hard for consumers to determine what prices they will face and what value of resources they will receive.

\section{Bundled Attributes}

The standard health insurance package bundles dozens of attributes, ranging from basic financial provisions such as deductibles, co-payments, and coinsurance, to separate pricing schedules for different medical conditions and different medical providers. Dilemmas abound. Should one purchase a plan with a lower premium but a higher deductible? Should one choose the policy that offers a private hospital room or the one with better mental health coverage? What about an add-on for pharmaceutical coverage?

We believe that, even ignoring the issues of time and uncertainty, consumers have trouble making wise decisions when faced with such complex consumption choices and pricing schedules. Realworld contexts provide ample evidence of decisions that are far from optimal even when informationgathering costs are low relative to the benefits of making the correct choice. ${ }^{16}$ These findings indicate that the difficulties cannot be rationalized as simply a matter of people weighing the costs and benefits of optimizing and then deciding that the losses from suboptimal behavior are less than the costs of optimizing. Rather, evidence from laboratory experiments in psychology (on pigeons, monkeys, and humans) indicates that poor choices when facing complex schedules reflects hardwired cognitive behavior patterns. ${ }^{17}$ Moreover, in cases of complex products with multiple attributes, competition will not, in general, prevent the exploitation of unaware consumers by optimizing firms. ${ }^{18}$

\footnotetext{
${ }^{16}$ John W. Pratt, David A. Wise, and Richard Zeckhauser, "Price Differences in Almost Competitive Markets, Quarterly Journal of Economics 93 (1979): 189--211.

${ }^{17}$ Richard J. Herrnstein, “The Matching Law,” in Papers in Psychology and Economics, edited by Howard Rachlin and David I. Laibson (Harvard University Press, 1997). Liebman and Zeckhauser also analyze domains in which individuals are
} 


\section{Complex Subsidies}

Complicated cross-subsidies riddle the health care system. They are one of the features that make it difficult for consumers to sort out decisions about health care and health insurance. These subsidies make it hard to perceive anything approximating marginal prices and also make it difficult to learn from friends, colleagues, and neighbors because those people likely face different subsidies and therefore different prices.

Both the government and employers use a wide range of instruments that can influence an individual's choices of health plans and health care and that make it difficult to infer the price one faces as a consumer. Consider a typical worker. The worker's employer pays most of the health insurance premium, and the government ignores the employer-provided health insurance in calculating the worker's taxable income. Do workers understand what the total premium paid on their behalf is, and that it results in a lower wage? Do most workers, or even most employers, understand the nature of the tax subsidies associated with health insurance? Moreover, what is the incidence model that applies here? In other words, what truly is the trade-off one faces if one lobbies one's employer for more generous insurance? Do firms reduce all salaries by the dollar amount of health insurance premiums, or do they apply a fixed percentage to the wage bill and effectively charge higher-paid employees more? Do older workers receive lower salaries than otherwise because they are more expensive to insure? And what happens in decentralized situations where fringe benefits are paid for at the center, whereas hiring decisions are primarily the responsibility of the periphery? These questions are unresolved in the health policy literature; workers certainly do not know the answers.

Inferring the effective price of one’s health insurance is further complicated because the pooling function of insurance causes people facing different risks to face the same insurance price. Within employee groups, the old are usually subsidized by the young, the high risk by the low risk, and at times,

likely to misperceive marginal prices. See Jeffrey Liebman and Richard Zeckhauser, “Schmeduling,” Harvard University, 2005.

${ }^{18}$ Xavier Gabaix and David Laibson, "Shrouded Attributes, Consumer Myopia, and Information Suppression in Competitive Markets,” Quarterly Journal of Economics 121 (2006): 505--40. 
the low paid by the high paid. Who ultimately pays these subsidies is a matter of debate. A typical, but unanswered, incidence question would be: If high-paid workers are charged more for their health insurance than low-paid workers, do their salaries adjust to reflect this? Do employers differentially lower the wages of women of childbearing age because they are likely to have maternity expenses? ${ }^{19}$ Of course, similar cross-subsidies exist in public insurance plans, such as Medicare and Medicaid, too.

It is worth noting that, whereas many of the behavioral phenomena we have identified suggest that people are likely to underconsume insurance and health care, the hidden employer premium payments are likely to lead to overconsumption because workers may not realize that they are sacrificing cash compensation in exchange for employer premium payments. Instead, workers may perceive their own premium payments as their sole opportunity cost for acquiring more generous insurance coverage. In the old days this did not matter, since health insurance costs were small relative to salaries. But it is not uncommon today for workers to get more than 10 or 20 percent of their effective income in the form of subsidized health insurance.

\section{Status Quo Bias}

Markets for health plans, like any markets, work best when individuals make effective choices among competing options. Unfortunately, even when faced with highly consequential choices and changed conditions, individuals have a tendency to stick with their prior choices. This tendency is called status quo bias. ${ }^{20}$ The original article on this subject provides evidence that, when Harvard employees allocated retirement savings or selected health plans, they had a strong inclination to stick with past decisions. There is the possibility, of course, that individuals stay with a health plan simply because it is optimal for them. To address this possibility, that analysis compared continuing employees and new employees of the same age. The analysis found that new employees chose plans significantly different

\footnotetext{
${ }^{19}$ The evidence suggests that the answer is, for the most part, yes. See Jonathan Gruber, “The Incidence of Mandated Maternity Benefits,” American Economic Review 84, no. 3 (1994): 622--41.

${ }^{20}$ William Samuelson and Richard Zeckhauser, “Status Quo Bias in Decision Making,” Journal of Risk and Uncertainty 1 (March 1988): 7--59.
} 
from the plans chosen by continuing workers of the same age, implying status quo bias. (This was a time of particular turmoil in health plans, with plans both entering and leaving the system, and premiums for employees changing dramatically; this turmoil explains why new employees made choices different from the original choices of the continuing employees.) Only 3 percent of the continuing employees changed plans in a given year.

It is particularly striking that so much inertia is observed in the context of health insurance. The annual election period solicits an active decision from participants each year, giving them only a short period in which to respond. To be sure, many companies automatically reenroll the employee in the same health plan should the employee fail to respond to the open enrollment form. However, even then, the fact that employees may need to adjust other benefits, particularly flexible spending accounts, which must be specifically elected each year, should diminish the use of default options. ${ }^{21}$ Nonetheless, there is little shifting across plans.

In recent years a literature has sprung up in behavioral economics on the importance of default options and their possible use for getting individuals afflicted with certain behavioral tendencies to make "wiser" choices, that is, choices that the experts recommend. ${ }^{22}$ Perhaps the best known illustration is the "save more tomorrow" scheme, wherein employees agree in advance to put a portion of their future salary increases into savings. ${ }^{23}$ With initial experiments, the savings rate went from 3.5 percent to 13.6 percent. The key elements were making a decision today that affected tomorrow not today (thereby avoiding hyperbolic discounting) and allocating only a portion of increases in earnings (thereby avoiding loss aversion).

\footnotetext{
${ }^{21}$ It is interesting that the Massachusetts health plan does not force people to elect a plan during a narrow enrollment window. Instead, people can enroll at any time, and the fine for noncompliance with the mandate is assessed continuously on a monthly basis rather than as an annual lump sum. We conjecture that a more discontinuous penalty schedule and shorter enrollment window might concentrate people's attention more and do more to overcome inertia and status quo bias.

${ }^{22}$ For an accessible introduction to this literature, see Richard Thaler and Cass Sunstein, Nudge (Yale University Press, 2008).

${ }^{23}$ Shlomo Benartzi and Richard Thaler, "Save More Tomorrow: Using Behavioral Economics to Increase Employee Saving," Journal of Political Economy 112, no. 1 (2004): S164--S187.
} 
The implicit approach of this paper is similarly pragmatic. Our analysis proposes that the design of health plans, and the framework for choosing among them, should be based on an understanding of behavioral tendencies, with an effort to encourage individuals to make the same choices they would make if they could consult at length with expert advisers. In effect, we are subscribing to the agenda of libertarian paternalism: “Equipped with an understanding of behavioral findings of bounded rationality and bounded self-control, libertarian paternalists should attempt to steer people's choices in welfarepromoting directions without eliminating freedom of choice.”24 That statement leaves open the question as to how welfare is to be measured. As we observe below, our welfare criterion is the maximum number of quality-adjusted life years (QALYs) available for the dollars spent on health care. We recommend that predictions of outcomes be done by experts but that we distill as best we can QALY preference values from individuals. ${ }^{25}$

\section{Implications for Health Care Policy}

The bottom line is that we doubt whether many insureds---whether they hold individual insurance, employer-based insurance, Medicare, or any other coverage---could accurately describe the combination of costs that they pay for their health insurance and the nature of payoffs, both financial and health related, that they might receive. These complexities make it extremely difficult for individuals to purchase insurance sensibly and, particularly, to choose among a wide range of policies that differ on many dimensions. Moreover, the same factors that hinder individuals from making wise choices as consumers also are likely to hinder people from making wise choices as voters, where (except under the most self-interested model of voter behavior) there is a need to understand elements of the health care system beyond their own circumstances.

\footnotetext{
${ }^{24}$ Richard H. Thaler and Cass R. Sunstein, “Libertarian Paternalism,” American Economic Review 93, no. 175 (2003): 6.

${ }^{25}$ We acknowledge that many of the same behavioral biases discussed here in the context of health insurance also arise in the contexts used to estimate QALY preferences, raising challenging questions about how one interprets existing estimates of willingness to pay for QALYs.
} 
But simply knowing that people may fail to optimize does not tell us the direction of the biases that result and the most appropriate government response. In this section, we discuss how conclusions about optimal health care subsidies are altered by the realization that people are not making wise choices. This analysis involves both efficiency and distributional considerations. In the next section, we apply these considerations specifically to the types of health care reform proposals currently being discussed at think tanks and by policymakers.

\section{Basis for Judging Outcomes}

Judging welfare implications of policies can be challenging when individuals are behaving in ways that diverge from the standard model in an economics textbook. In particular, when people’s preferences at different points in time are inconsistent, as in the case of hyperbolic discounting, or when people’s choices suggest that they lack coherent preferences, as when complexity causes them to give up on making a selection altogether, then the social planner typically needs to make a choice of which perspective is the best one---a choice that cannot be validated using revealed preference. ${ }^{26}$ On the other hand, when people are simply uninformed, the normative implications are generally straightforward. The social planner should set policies to try to obtain the same selections that individuals would have made had they been fully informed. Depending on the context and available technology, this might involve providing information, setting defaults that are best on average, or paternalistically compelling individuals to make the "right” choices.

Our general view is that since individuals are such poor decisionmakers in many health contexts, the traditional prescription for decentralized choices -- simply charge people the marginal resource cost of providing health care and go with their decisions -- will not in general result in the socially optimal

\footnotetext{
${ }^{26}$ B. D. Bernheim and A. Rangel, "Behavioral Public Economics: Welfare and Policy Analysis with Non-Standard Decision Makers,” Working Paper 11518 (Cambridge, Mass.: National Bureau of Economic Research, 2005).
} 
outcome. Instead, it will be necessary to evaluate different policies by measuring aggregate health outcomes, such as QALYs gained per dollar spent under the different policies. ${ }^{27}$

\section{Behavioral Economics as a Normative Justification for Subsidizing Insurance Purchase}

Most arguments for subsidizing health insurance come from one of four notions: that it generates externalities (for example immunizations), that it is a merit good, that it is a right, or that it helps to facilitate the creation of large risk-sharing pools. The fourth argument is essentially risk spreading after some lotteries have already been run, since subsidies will induce individuals who know they are at lower risk to join alongside those at higher risk when they are charged the same premium. ${ }^{28}$

We believe that behavioral considerations provide an additional reason for the subsidizing of health insurance and of health care. Begin with the standard diagram that illustrates how the moral hazard from insurance is exacerbated by the tax subsidy to employer-provided insurance. The $x$-axis of figure 1 measures the quantity of health care consumed. The line labeled $R R$ is the demand curve for health care that would result given insurance for a rational individual who understands probabilities, is an exponential discounter, and chooses in his own self-interest. Thus for example he understands that if he gets thrust more deeply into the medical care system, his care will be heavily subsidized via insurance. The SS line shows the social cost of providing medical care. Thus the socially efficient level of care is $Q^{e}$. Absent a tax subsidy for health insurance, the consumer purchases a level of insurance that reduces his marginal cost per unit of health care to II, causing the consumer to overconsume at $Q^{i}$. With the tax subsidy, the fully rational consumer purchases extra insurance, reducing his marginal cost of consuming care to $T T$, and further exacerbating overconsumption to $Q^{t}$.

Now introduce behavioral considerations. We start with the case where the consumer underconsumes insurance and then turn to the case where the consumer under-perceives the full cost of

\footnotetext{
${ }^{27}$ See Chernow, Rosen, and Fendrick, "Value-Based Insurance Design.”

${ }^{28}$ Subsidies for health care at point of delivery---such as low co-pays relative to marginal cost---simply represent the essence of insurance, since those who are sick are likely to lose income and have other financial costs.
} 
generous employer-provided insurance. Consider now a second demand curve, labeled $D D$. Line $D D$ is the demand curve of the mere mortal everyman, who does a poor job of looking down the road, procrastinates, is at best inadequate in considering probabilities, and so on. We have drawn the $D D$ curve well below $R R$, after engaging in our speculation of how most individuals behave. ${ }^{29}$ In particular, we have cleverly drawn the curve so that the consumer underconsumes if he buys unsubsidized insurance but consumes exactly the social optimum $Q^{e}$ with the insurance subsidy in place.

In this example, the lesson of the second best triumphs. Rather than exacerbating deadweight loss, subsidizing the purchase of health insurance moves us toward the social optimum. But is this empirically plausible? After all, the presence of generous insurance often reduces the consumer's price of obtaining care to something like 10 percent of the social cost. Could behavioral factors that encourage underconsumption be sufficiently large to offset such significant underpricing? The truth is that we have no empirical basis to judge. But it does not strike us as implausible.

In particular, there is disturbing evidence that relatively small changes in co-payments can have quite large impacts on utilization. ${ }^{30}$ This finding suggests that behavioral factors may be a big part of an underconsumption pattern. Could people mistakenly judge a 1-in-100 risk of a medical condition as a 1in-1,000 risk? Could people myopically discount adverse health outcomes thirty years in the future at an 8 percent rate rather than at a 2 percent rate, assuming that a 2 percent rate is appropriate, thereby underweighting these payoffs by a factor of five? These orders of magnitude do not seem out of the question.

Of course, for behavioral factors to justify a health care subsidy, the factors leading to underconsumption need to be sufficiently strong not only to outweigh the moral hazard effects of

\footnotetext{
${ }^{29}$ We have drawn the $D D$ curve to intersect the $x$-axis at a different point than the $R R$ curve. This implicitly assumes that the individual is not even good at determining when care would be good for him if the monetary cost is zero. That is not unreasonable, since there are the inconvenience and anxiety costs of going to the doctor.

${ }^{30}$ See Amitabh Chandra, Jonathan Gruber, and Robin McKnight, "Patient Cost-Sharing, Hospitalization Offsets, and the Design of Optimal Health Insurance for the Elderly,” Working Paper 12972 (Cambridge, Mass.: National Bureau of Economic Research, 2007). To the extent that adherence to cost-reducing therapies is lowered by cost sharing, the standard argument that consumers should be made more price sensitive in their health care consumption decisions is further weakened.
} 
insurance but also to outweigh any behavioral factors that lead to overconsumption. As we explain above, in the current U.S. system it is likely that the employer contribution to health insurance is underrecognized, causing people to negotiate excessively generous insurance packages from their employers, and thereby giving up too much in salary. If this is true, then the TT curve would shift down even further. A similar phenomenon among the electorate might cause older Americans to receive overly generous Medicare benefits, when they might prefer greater Social Security benefits instead.

It is worth emphasizing that there is a range of possible remedies for bad decisionmaking. Designing an optimal subsidy to offset human failures is only one such possibility. Another approach is to make the true prices and payoffs more transparent, so that even we simple humans can optimize correctly. In particular, providing information and providing it in a particularly salient way could be a much more efficient approach to achieving optimal consumption levels of health care since it would not require us to incur the deadweight loss of taxation to raise the revenue for the subsidies, including unnecessary subsidies to any sophisticated optimizers in the population. We think the transparency approach could be particularly fruitful in assisting consumers in perceiving the full cost of their health insurance. Employers could be required to either report annually to consumers the full cost of insurance or, better yet, add the employer share of premiums into gross wages on the paycheck (before subtracting it again as a pretax payroll deduction). ${ }^{31}$ To qualify for tax deductibility, employers could also be required to provide a fixed dollar subsidy to their employee's health plans, rather than offering proportional subsidies of, for example, 70 percent of any health plan's cost. And of course the tax subsidy for health insurance could be capped to avoid gold-plating. ${ }^{32}$

\footnotetext{
${ }^{31}$ Note that if the size of the underconsumption from behavioral factors exceeds the overconsumption from insurance but not the further overconsumption caused by the tax subsidy, it could be optimal to eliminate the tax subsidy but permit the misperception of the employer cost to persist.

${ }^{32}$ A particular challenge for firms is risk adjustment. Ideally, differences in prices across health insurance plans would not account for the differences in risk levels of employees enrolling in different plan options. Though this concept is well understood in theory, it is rarely implemented. It seems to be just too hard for employers to get the prices right.
} 


\section{Behavioral Economics as a Normative Justification for Subsidizing Small Costs}

It is important to note a distinctive aspect of health insurance that is quite different from what would be proposed for ordinary insurance. Small costs are heavily subsidized, not merely large costs. For example, insurance typically pays most of the cost for routine office visits.

In part, this structure can be seen as a response to loss aversion, where small costs count heavily relative to large ones. Thus individuals tend to like insurance that protects against relatively highfrequency, low-cost events. These are precisely the costs that individuals incur most frequently with their health care. Subsidizing such costs is a further way, apart from subsidizing insurance itself, to make health care insurance attractive to the typical prospect-theoretic individual. It thus helps to build up the size of the insurance pool.

But subsidizing small costs also has a more fundamental role in our conception of health care decisionmaking. These subsidies help overcome the underconsumption of health care by people who make bad decisions, forgoing small costs today that will in expectation produce greater benefits down the road. ${ }^{33}$ If one accepts this justification for subsidizing small health care costs, it is clear that the subsidies need to be carefully designed. A single price signal will not be enough to induce ordinary consumers to acquire the optimal amount of care. Consumers who are more likely to underconsume care will need greater subsidies, and subsidies will need to be greater for high-value consumption and for types of consumption where consumers are more likely to fail in their decisionmaking.

Given that co-payments are likely to be more of a discouragement to the health care use of lowincome consumers than of higher-income consumers, it is puzzling that we do not see much variation of co-payments with income. ${ }^{34}$ Someone earning $\$ 25,000$ might well be more discouraged by a $\$ 10$ co-pay than someone earning $\$ 40,000$ would be by a $\$ 25$ co-pay. Thus it seems clear that there should be

\footnotetext{
${ }^{33}$ Lest we be misunderstood, we are not concluding that insuring for small costs is desirable in health insurance. We are just pointing out that there are arguments in its favor. Structuring desirable subsidies should be a heavily empirical exercise.

${ }^{34}$ In contrast, some large employers (including ours) charge different premiums for the same health insurance based on salary.
} 
progressivity in co-payments, not merely in premiums. Note that we are not necessarily arguing for more progressivity overall, just consistent progressivity across the plan. ${ }^{35}$ It is also clear that there should be different co-payments for different types of visit and different subsidies for different types of care, a recommendation that others have also made. ${ }^{36}$

Recent evidence suggests that this sort of differential pricing can be successful. A study of a firm that decreased co-payments for five chronic medication classes finds that adherence to disease management protocols improved. ${ }^{37}$ Another study finds that increased cost sharing for retirees in California led to decreased usage of doctor's visits and prescription drugs and to additional hospitalizations, implying that reversing this cost sharing, or at least some of it, could provide important health benefits---and perhaps yield the complementary benefit of financial savings to the system. ${ }^{38}$ Even when preventive services and medicines treating chronic conditions are exempt from co-pays, consumers may have to pay for physician visits in order to access free services or prescriptions. However, one recent study finds that patients are not less likely to take advantage of free preventive services in these contexts. $^{39}$

We should not exaggerate the extent to which differential pricing is likely to produce benefits. Those advancing this approach frequently propose their favorite preventive interventions as candidates for subsidy, and the best surely do extremely well. But this is argument by anecdote, illustrating the availability heuristic from behavioral decision theory: People judge the relative frequency of an event by how easily an example can be brought to mind. ${ }^{40}$ Thus if we can readily think of some preventive

\footnotetext{
${ }^{35}$ The Massachusetts Commonwealth Care plan is an example of a plan that gets this right. Co-payments for primary care office visits are free for families with income below the poverty line, $\$ 5$ for families between one and two times the poverty line, and $\$ 10$ for families between two and three times the poverty line.

${ }^{36}$ Chernow, Rosen, and Fendrick, "Value-Based Insurance Design."

${ }^{37}$ Michael E. Chernow and others, "Impact of Decreasing Co-payments on Medication Adherence within a Disease Management Environment,” Health Affairs (Jan./Feb. 2008): 103--12.

${ }^{38}$ Amitabh Chandra, Jonathan Gruber, and Robin McKnight, "Patient Cost-Sharing, Hospitalization Offsets, and the Design of Optimal Health Insurance for the Elderly,” Working Paper 12972 (Cambridge, Mass.: National Bureau of Economic Research, 2007).

${ }^{39}$ John W. Rowe and others, "The Effect of Consumer-Directed Health Plans on the Use of Preventive and Chronic Illness Services,” Health Affairs (Jan./Feb. 2008): 113--20.

${ }^{40}$ Daniel Kahneman and Amos Tversky, “On the Psychology of Prediction,” Psychological Review 80 (1973): 237--5l.
} 
measures that would gain QALYs and save dollars, or even gain QALYs at a low price, we naively conclude that such measures are widespread.

To be sure, some important preventive measures do fall in the inexpensive QALY category. Those that are most prominently mentioned are countermeasures to tobacco smoking, alcohol misuse, physical inactivity, and poor diet. It has been estimated that curing these problems could prevent 900,000 American deaths annually, nearly 40 percent of the total yearly mortality in the United States. ${ }^{41}$ The U.S. Preventive Services Task Force identifies beneficial measures such as counseling adults to quit smoking, screening for colorectal cancer, and providing influenza vaccinations. ${ }^{42}$ The first thing to note about these interventions is that many of them relate to actions individuals have to take for themselves, such as eating healthily and exercising. These are activities that are beyond the scope of normal medical care and might be dealt with better in a workplace program than with the annual visit to the physician, where one gets a pep talk. The other interventions are highly specific within the health care system.

Let us assume that we want to encourage individuals to get colorectal screenings and influenza vaccinations; both offer QALY gains at negative cost. ${ }^{43}$ These services should certainly be highly subsidized. But maybe we should go further and actually pay people to get them. Should payment be implemented for all inexpensive QALY treatments? The answer is no. While there will be some services for which people should receive payment, there are other cases in which it would be a mistake. For payments to be potentially optimal, two conditions must hold. First, there must be some behavioral response to price. If the price elasticity is zero, then we are just randomly shuttling around money, which is disadvantageous. Second, there must be nonfinancial reasons (including any number of the behavioral concerns we raise above) for why people do not get the treatments. If there were no such nonfinancial reasons, we could simply offer the treatment for free and tell people to get it. Colorectal screenings,

\footnotetext{
${ }^{41}$ Ali H. Mokdad and others, “Actual Causes of Death in the United States,” Journal of the American Medical Association 291 (2004): 1238--45. Also see Joshua T. Cohen, Peter J. Neumann, and Milton C. Weinstein, "Does Preventive Care Save Money? Health Economics and the Presidential Candidates,” New England Journal of Medicine 7 (February 14, 2008): 661-63.

${ }^{42}$ Cohen, Neumann, and Weinstein, “Does Preventive Care Save Money?”

43 Ibid.
} 
where the whole process is unpleasant, and vaccinations, which at least require a jab, both meet the test for being services where it potentially makes sense to pay people to obtain the treatment. (The unpleasant nonfinancial aspect also minimizes the chance that individuals will just collect multiple treatments to pick up the cash.) Moreover, such payments, if implemented, might provide convincing signals to individuals that experts really thought the treatment yielded substantial expected health benefits.

Critical questions then are: How widespread are such preventive interventions? And how do they compare to traditional medical treatments? Fortunately, a recent study addresses these questions. ${ }^{44}$ It examined 1,500 cost-effectiveness ratios published in the literature from 2000 through 2005, in articles where future benefits and costs were properly discounted; 279 of these ratios applied to preventive measures and 1,221 to treatments. Surprisingly, the distribution of the ratios for prevention and treatments were much the same. Thus we conclude that prevention and treatment compete on relatively equal ground, given current practices. There are highly attractive interventions---and also poor ones--within each category.

There are other promising findings in the study. For both prevention and treatment, nearly 20 percent of procedures saved QALYs and costs simultaneously, and an additional 11 percent (prevention) and 16 percent (treatment) provided benefits for less than \$10,000 per QALY. Vaccinations, colonoscopies for older men, screening for some conditions in newborns where treatment can prevent debilitation, and high-intensity smoking cessation programs fall into these categories. But the study has some extremely disturbing elements as well. At the unfavorable end, 9 percent of procedures either cost more than \$1 million per QALY or actually both increase cost and worsen health. The implication of such findings is that there are significant gains to be made by promoting inexpensive QALY procedures and curtailing those that are exceedingly expensive per QALY or that actually hurt health and increase

\footnotetext{
${ }^{44}$ Ibid.
} 
cost. A prime example of the last is surgery in seventy-year-old men with a new diagnosis of prostate cancer, as opposed to the procedure of "watchful waiting.”

If we want to encourage more use of the inexpensive QALY procedures, and if we want to continue to rely on individuals to be the deciding voice in determining whether they get health care, the most immediate and promising instrument would seem to be the subsidy system, not the one administered by the IRS but the more elaborate one that is part of every health plan. Thus for example prostate surgery for elderly men might lose its major subsidy. By contrast, individuals might be paid to enroll in smoking cessation programs.

If health plans, or indeed employers or the government, are to use subsidies to influence healthrelated behaviors and medical treatment choices, they will have to attend carefully to behavioral propensities. This will require considerable amounts of experimentation to determine for example how much such factors as convenience, counseling from a physician, and dollar incentives matter when people are choosing their health-related activities.

\section{Optimal Provision of Anxiety-Reducing Care}

Traditional decision theory does not incorporate anxiety. All outcomes are assigned utilities at the end of the tree, with no acknowledgement of anxiety or dread along the way. But anxiety and its relief are major components of many individuals' encounters with the health care system. We argue, therefore, that anxiety should be treated as a valued component of utility and should go into life-year calculations.

Consider diagnostic testing. Some would say that it should be used only when it will affect medical treatment. But that approach ignores anxiety. Consider an individual who is suffering from persistent headaches. There are dozens of possible explanations, but one that is likely to leap to mind is a brain tumor. On a pure odds basis, this is quite unlikely, but it may be reasonable for a doctor to offer reassurance by providing a brain scan just to rule out the possibility. For some individuals, living with 
fear of a brain tumor may be as uncomfortable as living in constant pain. A procedure costing a few thousand dollars may relieve that concern. Anxiety, we speculate, is much less than proportional to the probability of an underlying medical condition. Thus a 1 percent risk may cause nearly as much distress as a 10 percent risk. Straightforward decision analysis will not get us to the right conclusion about medical care in such situations, if we take anxiety seriously.

Relief from anxiety does not always argue for more care or for more intensive care. It is now recognized that many women have had breast cancers that did not show up on ordinary mammograms. One possible recommendation is to proceed to MRI examinations, which are both more sensitive and more expensive, for these women. A prime argument against this approach is that MRIs produce many false positives, dangerous-looking situations that need to be biopsied. Given the availability of needle biopsies, the costs of such procedures---both in money and discomfort---are not exceedingly high. However, some doctors are hesitant to recommend turning to MRIs because they will significantly raise patients' anxiety levels when it is learned that a biopsy is required. We would argue to the contrary--that since the time from the MRI to the ultimate test results is short, the anxiety period is brief. This is different from a brain tumor scan, where anxiety is relieved for a very long period of time.

Our point is not to argue for laxity in deciding when to carry out medical procedures. There are clearly cases where procedures are high cost, low value, and anxiety producing. Instead, our point is that anxiety from health care procedures, the duration of that anxiety, and its probabilistic resolution should be taken into account when structuring subsidy systems in health care plans.

\section{Distributional Consequences of Heterogeneity in Behavioral Propensities and Preferences}

Some individuals are prey to behavioral biases. Others can mostly escape them. Unfortunately, the health care system can not readily distinguish between these two groups of people. Thus if the lessons of this paper are taken seriously, it will be important to determine the general distribution of different tendencies in the relevant populations. A system has to be designed to optimize health care, 
given the distribution of decision propensities in the population. This implies, of course, that the system will be poorly designed for some beneficiaries. If we subsidize health care to counter a general tendency toward underconsumption, those who neither have loss aversion nor are hyperbolic will end up overconsuming.

The system as a whole needs to be designed to succeed on average over the population. Nonetheless, there are opportunities for treatments to be chosen in response to the preferences of specific individuals. If you are a sixty-year-old male with prostate cancer, and your first visit is to a urologist, you will likely get a prostatectomy. A radiologist would steer you, by contrast, toward radiologic treatment. This need not be the case. One study developed a framework for eliciting patients’ preferences and incorporating them into the treatment of prostate cancer. ${ }^{45}$ If we wish to maximize QALYs for the dollars we spend, the health care system must recognize not only individuals’ common behavioral proclivities but also areas where they have distinctive preferences. As behavioral economists, we are willing to question whether people make good decisions, but we do not dispute that individuals vary in their underlying preferences.

\section{Implications for Current Policy Debates}

Historically, federal tax subsidies for health insurance have been dominated by the nontaxation of employer-provided health care, a tax expenditure projected to reduce income tax revenue by $\$ 168$ billion in 2009. This subsidy encourages the formation of workplace-based purchasing pools, reducing the adverse selection and high administrative costs problems of the individual market. It also encourages more people to buy health insurance and the purchasers to buy more of it, such as more comprehensive health plans. In short, this subsidy exacerbates the moral hazard problems stemming from insurance. The location of these purchasing pools at the workplace also has the potential to distort labor markets in

\footnotetext{
${ }^{45}$ Benjamin D. Sommers and others, “A Decision Analysis Using Individual Patient Preferences to Determine Optimal Treatment for Localized Prostate Cancer,” Cancer 110, no. 10 (2007): 2210--17.
} 
several different ways, such as by tying workers to jobs excessively. Moreover, the particular design of the existing subsidy system tends to foster adverse distributional consequences, though this could be corrected without abandoning employment-based health insurance, for instance, by capping the subsidy or turning it into a refundable tax credit. Standard policy analysis of this tax subsidy weighs the protection benefits it affords of increased insurance versus the various distortionary costs it creates.

The trend in policy proposals from both the left and the right is to propose options that would shift people away from employer-based coverage. The most ambitious plans on the left propose to replace private employer-based insurance with publicly provided insurance, via Medicare for all. Other plans retain private insurance but abolish employer-based insurance in favor of geographically based purchasing pools. ${ }^{46}$ More centrist plans, like the recently enacted Massachusetts plan, aim to maintain employer-provided coverage but introduce generous subsidies for those purchasing insurance through newly created purchasing pools. These pools will likely produce a modest shift away from employerbased coverage to the individual market. From the right, the most common plans attempt to "level the playing field” by providing equivalent subsidies to people purchasing insurance outside the workplace or by eliminating the employer-based subsidy altogether and providing tax credits to all who purchase insurance.

Other than the Medicare for all plans, each of these approaches would make individuals responsible for making additional, complex choices---both about which insurance plan to purchase and about the timing and quantity of health care consumption. Given that we believe it is unlikely that most individuals will make sensible decisions when confronted with these choices, this policy trend is troubling. Based on our analysis, we suggest four main lessons for health care reform:

---Consumers need to have their health insurance purchases mediated.

---Co-payments and subsidies should be designed using cost-effectiveness analysis.

---Efforts to cover the uninsured should reflect behavioral obstacles to coverage.

\footnotetext{
${ }^{46}$ Peter Diamond, “Organizing the Health Insurance Market,” Econometrica 60 (1992): 1233--54.
} 
---Information gathering on the effects of behavioral interventions should be increased.

\section{Mediating Health Insurance Purchases}

Health insurance is too complicated a product for most consumers to purchase intelligently. The employer-based system works well in this regard because employers have strong incentives to act as faithful agents for their employees in selecting a very limited number of health insurance options. Effective option selection is a public good: once conducted for one, it is available for all. Moreover, employers can bargain in monopsonistic fashion with insurers; individuals cannot. This bargaining power not only reduces premiums, it also largely eliminates post-claim underwriting, a practice in the individual market whereby insurance companies attempt to retroactively deny health insurance to people who get sick based on technicalities in their original insurance application.

In theory, some entity other than employers could act as the mediator. For example, the Massachusetts Commonwealth Connector offers a menu of standardized plans to individual purchasers. While the Massachusetts experience bears watching, we are dubious, for several reasons, that public sector mediators will perform as well as employers currently do. First, public sector mediators will be under pressure to offer every qualified plan. Thus they will likely offer a much more extensive menu of options than most employers do. The failure to weed out the less desirable plans will lead many consumers to make poor purchases. The Massachusetts Commonwealth Choice plan brags that it offers “dozens of options.”, To choose among them is surely a challenge for most individuals. In contrast, the typical employer offers at most a handful of insurance options and, in many cases, just a single plan.

Second, public sector mediators will likely assemble plans for broader population groups and respond to consumer tastes only indirectly via the political system. Employers are likely better able to tailor plans to the needs of their workforce and to revise plans if their workers are unsatisfied with them. Third, employers, particularly large employers, may be more effective than the public sector in persuading providers to implement innovative cost-saving and quality-improving measures. 
It is also possible to imagine that mediators could emerge from the private sector, quite apart from employers. If consumers value these sorts of service, they could hire health insurance "agents” to help them buy insurance packages. This possibility strikes us as a recipe for very high administrative costs, at best, and for disaster, at worst. There are many examples involving complex products for which competition fails to drive out high-cost or low-quality providers. Consumers persist in buying mutual funds with annual fees of 1.25 percentage points. Large price spreads, on the order or more than five to one, continue to exist for identical Medigap policies. ${ }^{47}$ Many consumers fail to choose the appropriate Medicare Part D prescription plan. ${ }^{48}$ Furthermore, evidence ranging from the U.S. subprime mortgage market to the U.K. pension mis-selling scandal shows the problems that can arise when consumers are left to rely on private sector mediators to help them buy complex products. The basic problem is that such mediators would typically represent the consumers for only one decision. Hence conflicts of interest on this purchase, such as steering customers to favored firms or shortchanging them on time, must be expected. An employer, by contrast, is engaged with employees on a continuing basis and also has a financial interest in their good health.

The current employer-based system appears to us to offer an unusual combination of aligned incentives, innovative capacity, and easy capitalization on the public goods aspects of insurance purchases. These advantages may well be enough to outweigh any labor market distortions that occur from commingling health insurance and employment. Indeed, the most serious of such distortions are being addressed through portability legislation.

\section{Designing Co-payments and Subsidies}

Many reform proposals appear to be guided by the goal of having consumers come as close as possible to facing the social price of producing care. The author of a prominent textbook concludes that

\footnotetext{
${ }^{47}$ See http://findarticles.com/p/articles/mi_m0EIN/is_2004_August_16/ai_n6162126.

${ }^{48}$ Jeffrey R. Kling and others, “Misperception in Choosing Medicare Drug Plans,” 2008. Brookings Institution.
} 
the "optimal health insurance policy is one in which individuals bear a large share of medical costs within some affordable range, and are only fully insured when coverage becomes unaffordable.”^49

Our analysis suggests that this is the wrong benchmark. Most humans do not act as fully informed, rational individuals who understand probabilities, do exponential discounting, and choose in their own self-interest. This means that the traditional prescription for decentralized choices---simply charge people the marginal resource cost of providing health care and go with their decisions---will not in general result in the socially optimal outcome. Instead, insurance subsidies and co-payment rates should be set to maximize a cost-effectiveness measure of health outcomes relative to dollars spent. These subsidies and rates will need to reflect the true behavior patterns of consumers rather than the theoretical patterns of economic textbooks.

The second element of this lesson is that not all therapies, office visits, and interventions should be treated equally. The underlying goal should be to promote QALYs, and some treatments are much better at doing that than others. Subsidies should be targeted at highly cost-effective treatments. Some high-cost, low-value treatments should get no subsidy whatsoever; indeed some should be taxed.

\section{Understanding the Behavioral Obstacles to Coverage}

The standard model of the uninsured envisions those individuals as crafty calculators who have figured out that insurance is costly to them because they are in a risk pool that charges more than their expected cost and because the benefits of insurance are truncated by the option of falling back on uncompensated care if they experience a medical emergency. This model inspires plans to assess financial penalties on those who remain uninsured as a way to change this calculus.

Our analysis of behavioral propensities suggests that underinsurance may be more a feature of inertia, complexity, and status quo bias than one of financial calculation. If we are right, efforts to expand insurance coverage should focus more on finding ways to automatically enroll people into a

\footnotetext{
49 Jonathan Gruber, Public Finance and Public Policy (New York: Worth, 2005), p. 409.
} 
default health insurance plan than on punitive financial incentives. The default plan should allow an optout option, for example, so as not to punish those who are liquidity-constrained because they locked themselves into lumpy consumption commitments, such as home mortgages. In our conception, the threat of financial penalties for those who fail to purchase health insurance may be a useful tool not because it tilts their financial calculus but rather because loss-adverse consumers hate penalties to an irrational degree. Thus the threat of penalties may be what enables them to overcome inertia and enroll in health insurance.

\section{The Need for Additional Data}

One implication of the inability of individuals to make good decisions on their own is that someone else must help make those decisions. This places an extraordinary information burden on the mediators who set up the default insurance plans and determine their subsidy and co-pay levels.

How should mediators, whether employers or the government or someone else, know what types and levels of subsidy produce what types of behavior? Fortunately, the field of behavioral decisionmaking explores a broad range of biases, such as prospect theory, hyperbolic discounting, and heuristic reasoning. The field draws on thousands of experiments and many dozens of field studies. It has now moved to actually monitoring people’s brains with MRIs to assess how information is processed.

However, such understanding merely points us in profitable directions. It does not explain the relevant real-world elasticities or how people respond to monetary incentives when factors such as pain, avoided morbidity, inconvenience, and anxiety are added. Thus we need to make major new investments in statistical studies, including randomized experiments, focused on measuring how individuals respond to the wide range of tools we have for modifying their health insurance and health consumption choices. Given that we can not rely on individuals to more than crudely approximate the maximization of their own health outcomes, these studies must focus on measuring health outcomes directly. 
The ability to learn from experience is one unambiguous advantage of employer-based health insurance. Employers design offerings that differ, and in theory we can look at the data and see how individuals respond. Justice Louis Brandeis once remarked on a crucial advantage of the federal system: “A single courageous State may, if its citizens choose, serve as a laboratory” for innovative programs. When employers are the laboratories, this power of experiment is greatly magnified. We can learn about the potential for more tiers on a pharmaceutical subsidy program, how risk adjustment works in practice, or what differences emerge when employers hand out fixed versus proportional subsidies for the premiums of alternate insurers. The ability to learn from experience also provides a strong argument for standardizing information technology throughout the health insurance sector so as to enable better data collection.

\section{Summary}

The field of health insurance provides a compelling arena in which to employ behavioral economics as a policy guide. That discipline enables us to predict the biases that afflict individuals’ poor decisions, to know what measures can counteract them, and thereby to produce better choices for insurance and care by individuals. QALYs are waiting to be reaped. 
Figure 1

Optimal Subsidies

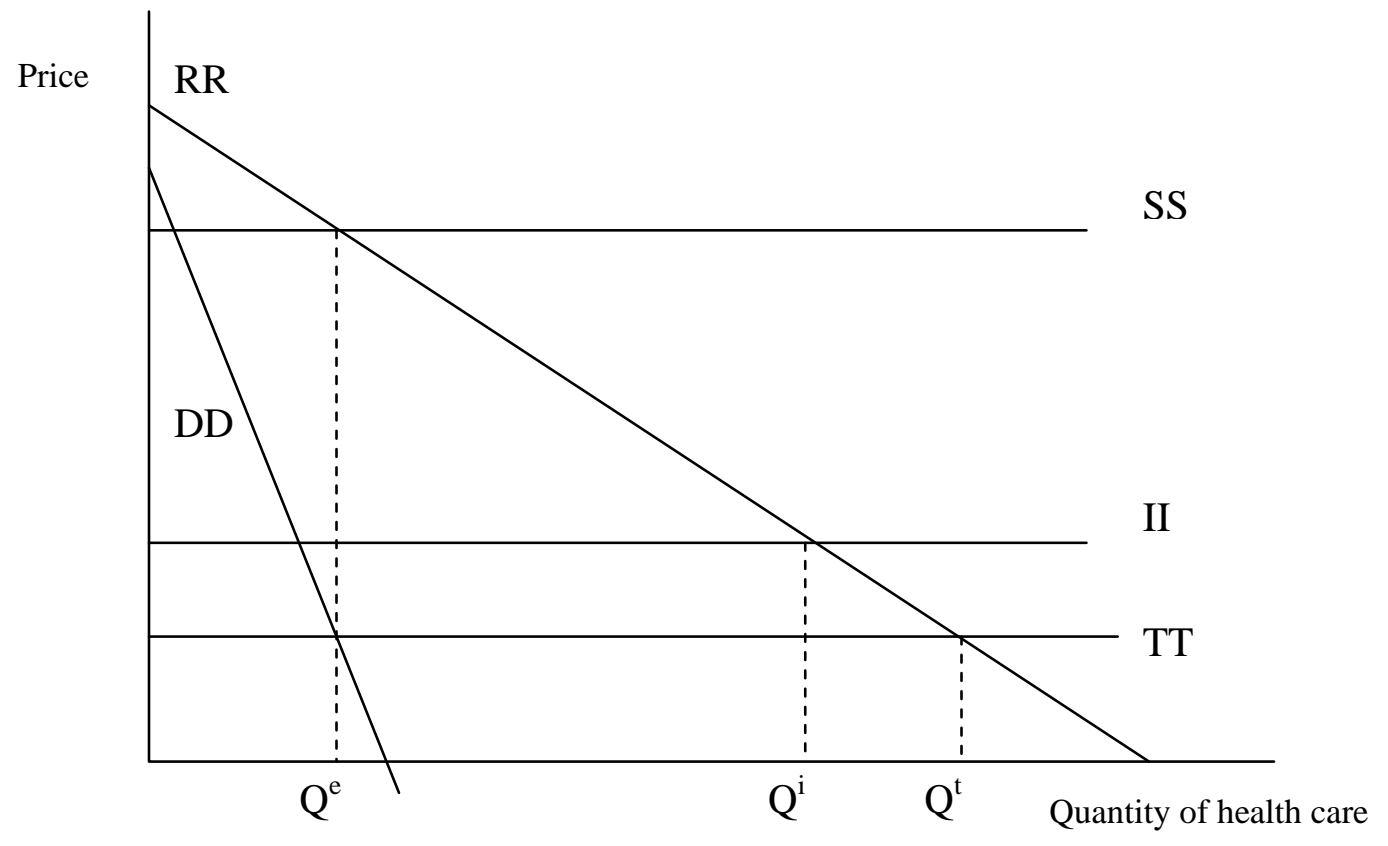

